\title{
The histological changes attributed to intermittent negative pressure on mice skin
}

\author{
Osama S. Abbadi ${ }^{1}$, Dalal S. Idris ${ }^{2}$, Khalid M. Nafie ${ }^{3}$ \\ 1 Department of Biochemistry, Faculty of medicine, Omdurman Islamic University, Sudan \\ 2 King Abdulaziz Center for Cardiology and Cardiac Surgery, Ryiadh, Saudi Arabia \\ 3 Department of Pathology and Laboratory Medicine, Prince Mishari bin Saud Hospital, Saudi Arabia \\ *Corresponding Author: Dr. Osama S. Abbadi, Department of Biochemistry, Faculty of medicine, Omdurman Islamic University, \\ Sudan. Email: aslikhalis@yahoo.com \\ Received: December 03, 2019; Accepted: December 29, 2019

\begin{abstract}
Background: Modern applications of negative pressure in healthcare include wound therapy, assisted child delivery, sleep apnea, and liposuction. Studies in negative pressure effects in the skin are scarce but promising. Objectives: To study the changes that could occur to the skin and subcutaneous tissue after exposure to two weeks period of intermittent negative pressure, using the albino mice as a model. Study design: Experimental animal study. Materials and methods: Ten albino mice were subjected to two sessions/day of intermittent negative pressure (INP) for two weeks. The tested skin areas were then excised for histology examination and compared with a control patches from the same mice. Skin biopsies were stained with H\&E (Harris Hematoxilin), Mayer's Hematoxilin, and Masson's trichrome stain. The slides were reviewed by pathologists and photographed. Results: The test slides showed marked loss of sebaceous glands and hair follicles, increased condensation of collagen, inflammatory features in the form of white blood cells infiltrations and edematous patches. Conclusion: Applying INP to the skin of albino mice results in the reduction of sebaceous glands and hair follicles, and evident signs of inflammatory changes.
\end{abstract}

Keywords: Intermittent Negative pressure, Sebaceous glands, Hair follicles.

\section{INTRODUCTION}

Negative pressure is a general term used to describe a pressure that is lower than the atmospheric pressure [1]. Negative pressure was useful in medical practice thousands of years ago, when Chinese invented cubbing therapy [2], and spread to Europe [3], and then to the Middle East [4]. Started by manual suction by mouth and a horn, cubbing evolved till recent days which became performed by clean vacuum cups and automated machines [2]. Negative pressure constitutes the basis of negative pressure wound therapy NPWT used for healing of Diabetic wounds and other wounds of chronic etiology [5-10]. Other uses of negative pressure in medicine includes erectile dysfunction management, where the use of vacuum erection devices-VEDs, proved efficiency [11,12], also it is used in assisted childbirth [13], in reducing the prevalence of sleep apnea [14], in nasal septum defect correction [15], and in liposuction $[16,17]$. Studies on the lower limbs of healthy individuals revealed that application of intermittent negative pressure improved the microcirculation and increased the blood perfusion [18]; an explanatory finding to the negative pressure wound healing capacity [19]. Although it proved great aid to wound healing and circulatory improvement, the pain and swelling during the suction site constitute a major complain from the candidates [20,21,22], nevertheless, the outcome is far greater in prospect than the transient pain and discomfort [21]. Despite the great results achieved by NPWT, still how it evokes healing and closure of wounds, is uncertain [23], but it is postulated that the vacuum process encourages wound healing and closure, presumably by increasing local hemodynamic circulation and vessels proliferation $[5,23,24]$, isolating the skin area from bacteria, and stimulating cell regeneration $[5,23]$. It would be of a great value to detect the histological changes of skin and subcutaneous tissue after subjection to intermittent negative pressure (INP). Mierte et al. studied how the dermis and epidermis changes in structure within scar tissue postvacuum [25]; they noticed a significant reduction in the epidermal thickness and increase in the dermis layer girth. Unfortunately, the changes were transient, and diminished after about two hours; nevertheless, this 2016 study gave hope about the possibility of vacuum to enhance the extracellular matrix (ECM) remodeling and proliferation. The writers themselves attribute the increased dermal thickness to edema [25], which is probably due to the prolonged time interval used in this study. This current experiment was held to study changes in the histological structure of healthy mammalian skin in response to 
two weeks of exposure to INP, taking the albino mice as a model. Skin represents an optimal tissue to carry on a negative pressure experiment, being in direct contact with INP process.

\section{MATERIALS AND METHOD}

Ten male albino mice were used in this experiment. First, Mice were sedated by inhalation of ether in a sealed fiberglass chamber. Two diamond shaped patches, each of them was $2 \times 2$ $\mathrm{cm}$, were shaved in the lateral abdominal wall of each mouse; one patch used as a control and the other were used as a test to perform INP. Negative pressure was applied on an interval of 10 seconds pump and ten seconds for rest, using a $50 \mathrm{ml}$ syringe: the syringe was trimmed and cut by the edges to offer a wider space at the tip; see figure? The pressure was in the range of $(-20$ to -25$)$ mmhg. Caliberation of pressure was through a pressure gauge, by which, the grading within the syringe shaft was marked at $(-20$ to -25$)$ mmhg. Each mouse was subjected to the INP cycle continuously for five minutes, two times daily for two weeks. The skin of both test area and control was excised in a quick and clean manner. Wounds healed within eight days through contraction, and hair grew back in the experiment site. Skin samples were put in 10\% formaldehyde, and blotted in paraffin within three days of preservation. Slides were obtained from the samples by Leica ${ }^{\circledR}$ microtome. Thirty clear slides were prepared. The following histological stains were applied for test and controls:

1. Hematoxilin and Eosin (H\&E) stain, particularly Harris Hematoxilin.

2. Mayer's Hematoxilin to highlight the nuclei.

3. Masson's Trichrome stain for collagen.

The slides were photographed through a microscope by the pathologist, who commented on the findings. The study underwent for two weeks, after which, the mice were returned to the center of veterinary researches, Khartoum, Sudan. All the procedures were performed according to the Institutional Animal Care and Use Committee guidelines [26].

\section{RESULTS}

H\&E stain showed features of inflammatory reaction including the presence of edema and increased white blood cells (WBCs). There was marked reduction in the number of hair follicles and sebaceous glands; See figure (1)

Mayer's hematoxilin stain revealed the normal appearance and positioning of nuclei within the cytoplasm. See figure (2).

Masson's trichrome staining showed that Collagen appears denser and better organized in the test slides when compared to the control; revise figure (3).

\section{DISCUSSION}

To summarize the findings, it is comprehensive to say that inflammatory changes were documented by the edema and increased inflammatory WBCs. Clues of cellular distortions noticed as patchy areas of epithelial disorganization. There was a distinctive reduction in the number of both sebaceous glands and hair follicles. Edema and infiltration of white blood cells could be attributed to the traumatic effect of INP; trauma is known to elicit an immune response [27]. Another possible cause of the inflammatory signs could be a concomitant inflammatory pathology such as an infection, although is very unlikely to have infectious incidents in all the thirty samples. Epithelial cells are distorted mainly because they are in direct contact with the negative suction power. A good possible explanation for the marked reduction in number of the sebaceous glands and hair follicles is the reduced blood perfusion due to the INP, which lead to the atrophy of their cells. Sebaceous glands could be absent because of an autoimmune disease or reaction, as also for the hair follicles, but the two speculations are arbitrary, since the tissue samples were extracted from several mice, and no visible changes-such as skin dryness or alopecia patches, were noticed. Against what was predicted, the collagen concentrations did not increase (significantly), even active fibroblasts were not detected, and this applies to all histological sections it could be because tissues were subjected to INP for only three to four weeks and then immediately excised for histology; complete collagen organization needs more than that time.
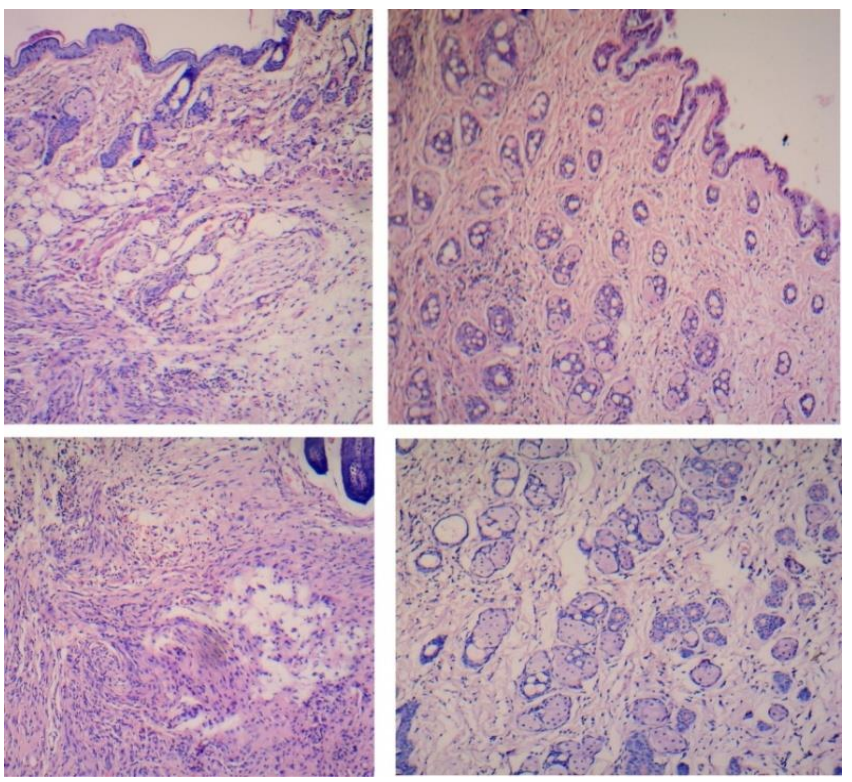

Figure 1: H\&E stained slides, where the left is the test and the right $x 4$ (c \&d $x 20)$ shows the control; notice irregular connective tissue alignment, and the ill defined cells with areas of edema and signs of inflammation. The hair follicles and sebaceous glands are almost absent.
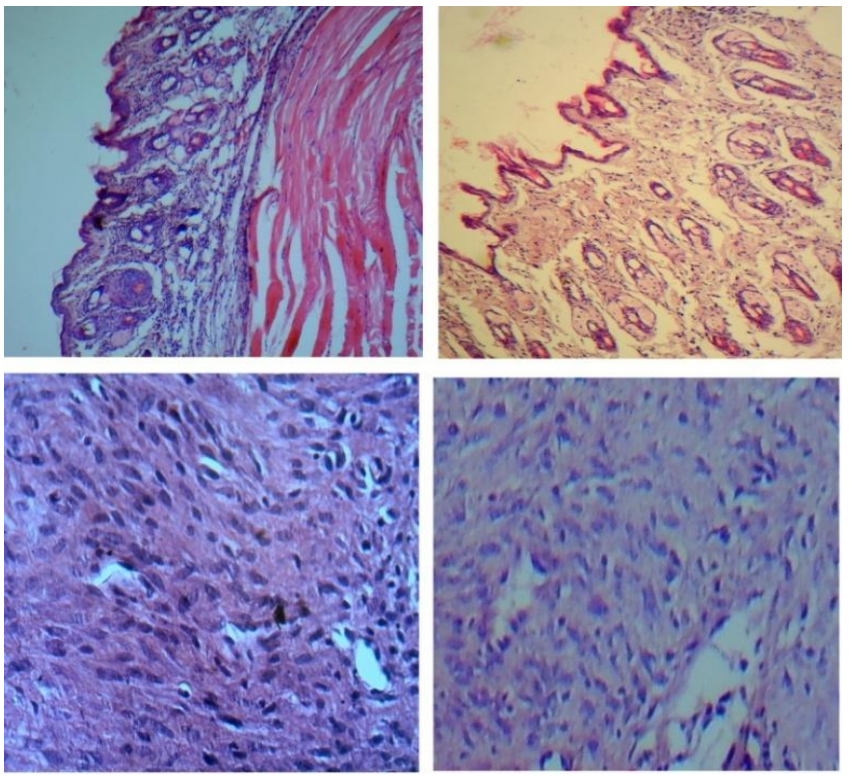

Figure 2: Mayer's hematoxilin stain-for the nuclei and cytoplasm. No differences were detected concerning nuclei appearance, shape, or positioning within the cytoplasm. Left sides are the test slides, and right sides are the controls. 


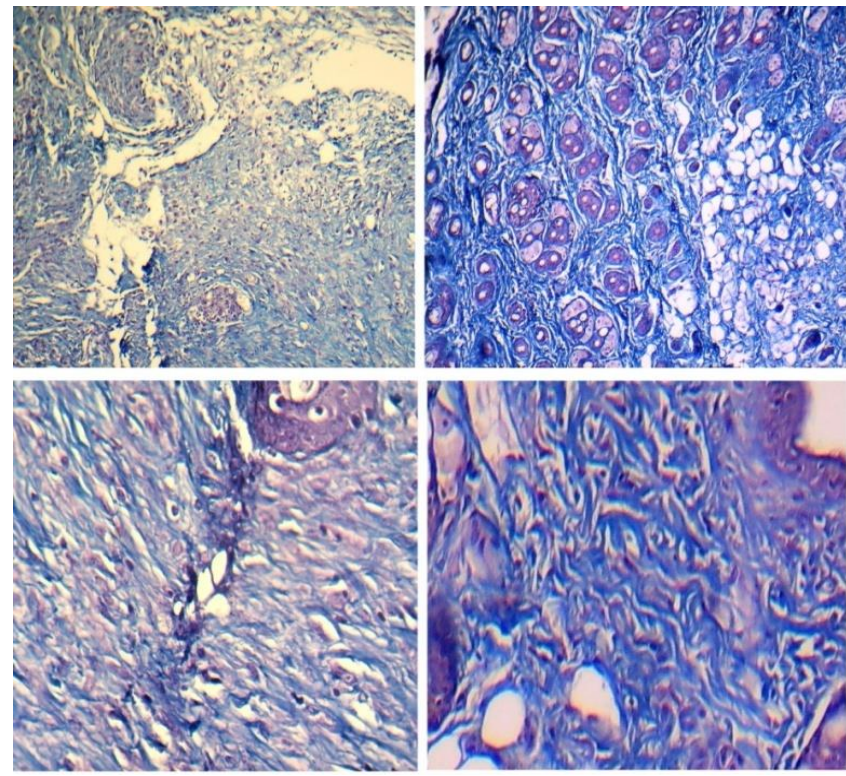

Figure 3: Masson's trichrome staining in test slides -left, and control-right. Notice the thicker and more ordered collagen (appear as blue streaks) on the test slides.

\section{CONCLUSION}

When a healthy mouse skin is subjected to intermittent negative pressure of $(-20$ to -25$)$ mmhg for two weeks, the number of both sebaceous glands and hair follicles are expected to decrease and the thickness of collagen increases and changes its shape to a more organized arrangement. Features of inflammation such as WBCs infiltration could be transiently noticeable.

\section{Conflict of Interest}

All authors declare that there are no conflicts regarding the article.

\section{Financial Support}

None declared.

\section{Author contributions}

Dr. Osama S. Abbadi designed the study, and carried the practical procedure; Dr. Dalal S. Idris participated in the development of the practical procedure, specimen preparation, and discussion writing. Dr. Khalid Nafie Fadelemula is the histopathology counselor and the critical reviewer of the experiment.

\section{REFERENCES}

1. The institute of Measurement and Control. Guide to Measurement of pressure and Vacuum. 1st ed. London. c1998.

2. Qureshi NA, Ali GI, Abushanab TS, El-Olemy AT, Alqaed MS et al. History of cupping (Hijama): a narrative review of literature. J Integr Med. 2017 May; 15(3): 172-181. doi: 10.1016/S20954964(17)60339-X

3. Abbas Zaidi SM, Jameel SS, Jafri K, Khan SA, Ahmad E. Ilaj bil hijamah (cupping therapy) in the Unani system of medicine: anecdotal practice to evidence based therapy. Acta Med Hist
Adriat. 2016 Aug;14(1):81-94. PMID: 27598955.

4. Vakilinia SR, Bayat D, Asghari M. Hijama (Wet Cupping or Dry Cupping) for Diabetes Treatment. Iran J Med Sci. 2016 May;41(3):S37. PMID: 27840503.

5. Rhee SM, Valle MF, Wilson LM, Lazarus G, Zenilman JM et al. Negative Pressure Wound Therapy Technologies for Chronic Wound Care in the Home Setting. Agency for Healthcare Research and Quality (US): Technology assessment report. 2014 Sep. PMID: 25905154.

6. Blume PA, Walters J, Payne W, Ayala J, Lantis J. Comparison of negative pressure wound therapy using vacuum-assisted closure with advanced moist wound therapy in the treatment of diabetic foot ulcers: a multicenter randomized controlled trial. Diabetes Care. 2008 Apr;31(4):631-6. doi: 10.2337/dc07-2196.

7. Schwartz JA, Goss SG, Facchin F, Gendics C, Lantis JC. Singleuse negative pressure wound therapy for the treatment of chronic lower leg wounds. J Wound Care. 2015 Feb;24 (2):4-9. doi: 10.12968/jowc.2015.24.

8. Ross RE, Aflaki P, Gendics C, Lantis Ii JC. Complex lower extremity wounds treated with skin grafts and NPWT: a retrospective review. J Wound Care. 2011 Oct;20 (10) : 490, 4925. doi: 10.12968/jowc.2011.20.10.490.

9. Dumville JC, Hinchliffe RJ, Cullum N, Game F, Stubbs N et al. Negative pressure wound therapy for treating foot wounds in people with diabetes mellitus. Cochrane Database Syst Rev. 2013 Oct 17;(10):CD010318. doi: 10.1002/14651858.CD01 0318.pub2.

10. Yarwood-Ross L, Dignon AM. NPWT and moist wound dressings in the treatment of the diabetic foot. Br J Nurs. 2012 Aug 9-Sep 12;21(15):S26, S28, S30-2. doi: 10.12968/bjon.2012.21. Sup20.S26.

11. Sun L, Peng FL, Yu ZL, Liu CL, Chen J. Combined sildenafil with vacuum erection device therapy in the management of diabetic men with erectile dysfunction after failure of first-line sildenafil monotherapy. Int J Urol. 2014 Dec;21(12):1263-7. doi: 10.1111/iju.12564.

12. Lin $\mathrm{H}$, Wang $\mathrm{G}$, Wang R. Application of the vacuum erectile device in penile rehabilitation for erectile dysfunction after radical prostatectomy (in Chinese). Zhonghua Nan Ke Xue. 2015 Mar;21(3):195-9. PMID: 25898548.

13. Suwannachat $B$, Lumbiganon $P$, Laopaiboon $M$. Rapid versus stepwise negative pressure application for vacuum extraction assisted vaginal delivery. Cochrane Database Syst Rev. $2008 \mathrm{Jul}$ 16;(3):CD006636. doi: 10.1002/14651858.CD 006636.pub2.

14. Kato S, Isono S, Amemiya M, Sato S, Ikeda A et al. Submental negative pressure application decreases collapsibility of the passive pharyngeal airway in non-obese women. J Appl Physiol (1985). 2015 Apr 1;118(7):912-20. doi: 10.1152/ japplphysiol. 00158.2014.

15. Skoulakis CE, Papadakis CE, Manios AG, Prokopakis EP, Nikolidakis AA et al. Negative pressure suction in nasal septum surgery. Rhinology. 1999 Jun;37 (2): 86- 7. PMID: 10416255.

16. Rodriguez RL, Condé-Green A. Quantification of negative pressures generated by syringes of different calibers used for liposuction. Plast Reconstr Surg. 2012 Aug; 130(2):383-384. doi: 10.1097/PRS.0b 013e 31825903b8.

17. Kahveci R, Rehimli M, Esmer A, Rehimli S, Kanturk R et al. A useful technique to obtain adequate negative pressure for liposuction. J Plast Reconstr Aesthet Surg. 2009 Dec; 62(12):e604-5. doi: 10.1016/j.bjps.2008.11.063.

18. Sundby $\varnothing \mathrm{H}$, Høiseth LØ, Mathiesen I, Jørgensen JJ, WeedonFekjær $\mathrm{H}$ et al. Application of intermittent negative pressure on the lower extremity and its effect on macro- and microcirculation in the foot of healthy volunteers. Physiol Rep. 2016 Sep; 4(17): e12911. doi: 10.14814/phy2.12911.

19. Sundby $\varnothing \mathrm{H}$, Høiseth LØ, Mathiesen I, Jørgensen JJ, Sundhagen $\mathrm{JO}$ et al. The effects of intermittent negative pressure on the lower extremities' peripheral circulation and wound healing in four 
patients with lower limb ischemia and hard-to-heal leg ulcers: a case report. Physiol Rep. 2016 Oct; 4(20): e12998. doi: 10.14814/phy2.12998.

20. Waldie K. Pain associated with negative pressure wound therapy. Br J Nurs. 2013 Mar 28-Apr 10;22(6):S15-6, S18-21. doi: 10.12968/bjon.2013.22.Sup4.S15.

21. Upton D, Stephens D, Andrews A. Patients' experiences of negative pressure wound therapy for the treatment of wounds: a review. J Wound Care. 2013 Jan;22(1):34-9. doi:10.12968/jowc.2013.22.1.34.

22. Upton $D$, Andrews A. Pain and trauma in negative pressure wound therapy: a review. Int Wound J. 2015 Feb;12(1):100-5. doi: 10.1111/iwj.12059.

23. Schintler MV. Negative pressure therapy: theory and practice. Diabetes Metab Res Rev. 2012 Feb; 28(1) : 72-7. doi: 10.1002/dmrr.2243.

24. Erba P, Ogawa R, Ackermann M, Adini A, Miele LF et al. Angiogenesis in wounds treated by microdeformational wound therapy. Ann Surg. 2011 Feb;253(2):402-9. doi: 10.1097/SLA. 0b013 e31 8 20563a8.

25. Meirte J, Moortgat $\mathrm{P}$, Anthonissen M, Maertens K, Lafaire $\mathrm{C}$ et al. Short-term effects of vacuum massage on epidermal and dermal thickness and density in burn scars: an experimental study. Burns Trauma. 2016 Jul 8;(4):27-9. doi: 10.1186/ s41038 -016-0052-x. eCollection 2016.

26. Office of Laboratory animal welfare. Institutional Animal Care and Use Committee Guidebook. 2nd ed. Bethesda (MD): National Institutes of Health; c 2002.

27. Pugin J. How tissue injury alarms the immune system and causes a systemic inflammatory response syndrome. Annals of Intensive Care. 2012;2:(27). doi: 10.1186/2110-5820-2-27. 